УДК 616.895 .8

Для цитирования: Васильченко К.Ф., Дроздовский Ю.В. Социальное функционирование и адаптация пациентов с первым психотическим эпизодом: внутренняя стигма и социально-психологические факторы. Сибирский вестник психиатрии и наркологии. 2018; 3 (100): 10-15. https://doi.org/10.26617/1810-3111-2018-3(100)-10-15

\title{
Социальное функционирование и адаптация пациентов с первым психотическим эпизодом: внутренняя стигма и социально-психологические факторы
}

\section{Васильченко К.Ф., Дроздовский Ю.В.}

Омский государственный университет

Россия, Омск, 644099, ул. Ленина, 12

\section{PEЗЮME}

В статье приведены результаты исследования самостигматизации, социального функционирования и адаптации пациентов с первым психотическим эпизодом при шизофрении и шизоаффективном расстройстве. Цель исследования: разработка принципов реабилитации у пациентов, перенесших первый психотический эпизод при шизофрении и шизоаффективном расстройстве, на основе оценки их социального функционирования, адаптации, самостигматизации и социально-психологических факторов. Материал: 134 пациента с установленным диагнозом шизофрении и шизоаффективного расстройства, соответствующие критериям первого психотического эпизода. Методы: клинико-психопатологический, психометрический (PSP, PANSS, «SS Measure») и статистический. Обнаружены статистические значимые различия показателя самостигматизации при разных особенностях воспитания в семье, наследственной отягощенности, семейного положения, образования, а также компенсаторно-приспособительных защитах.

\section{Ключевые слова: первый психотический эпизод, шизофрения, самостигматизация, адаптация.}

\section{ВВЕДЕНИЕ}

Социальное функционирование и адаптация пациентов с широким спектром психических расстройств в последние годы представляет большой интерес для исследований в силу установившейся в современной психиатрической науке биопсихосоциальной модели [1]. Показано, что адаптация и социализация как фактор эффективности терапии во многом зависят не только от внутренних резервов пациента, но и от его социального окружения, в первую очередь от его родных и близких $[2,3,4,5$, 6]. В обществе по-прежнему существуют давно сложившиеся нелицеприятные стереотипы о людях с психическими расстройствами [7, 8]. Когда пациент впервые оказывается в стенах психиатрического стационара, известные ему предубеждения обращаются против него самого, формируя такой феномен как «самостигматизация», или «внутренняя стигма» $[9,10]$. В свою очередь этот негативный фактор может приводить к депрессивным реакциям на наличие психического расстройства либо снижению комплаентности $[11,12]$. Учитывая пластичность психопатологических процессов, характерную для ранних этапов заболевания, наилучший ответ на проводимые психофармакологические и психосоциореабилитационные мероприятия определяется именно в этот период [12].

Целью предпринятого нами исследования является разработка принципов реабилитации у пациентов, перенесших первый психотический эпизод при шизофрении и шизоаффективном расстройстве, на основе оценки их социального функционирования, адаптации, самостигматизации и социальнопсихологических факторов.

\section{МАТЕРИАЛЫ И МЕТОДЫ}

В исследуемую выборку вошли 134 пациента с установленным диагнозом параноидной шизофрении (F20.096, F20.016) и шизоаффективного расстройства (F25), госпитализированные в отделение первого психотического эпизода (БУЗ Омской области «КПБ им. Н.Н. Солодникова») в период с 2015 по 2017 г.

Критериями включения были следующие условия: установленный согласно МКБ-10 диагноз параноидной шизофрении или шизоаффективного расстройства, длительность заболевания не более 5 лет, количество госпитализаций в анамнезе не более 3 , а также наличие переживаний внутренней стигмы. Всеми пациентами подписано добровольное информированное согласие на участие в клиническом исследовании.

По гендерному признаку выборка была разделена следующим образом: 45,5\% мужчин $(\mathrm{n}=61)$ и 54,5\% женщин $(\mathrm{n}=73)$. Медиана возраста в группе мужчин составила 24 [22; 29,5] года, в группе женщин - 30 [26; 38] лет.

В исследовательской выборке выявлено преобладающее большинство пациентов с установленным диагнозом параноидной шизофрении: для группы с периодом наблюдения менее 1 года (F20.096) объемная доля составила 40,3\% (n=54), для пациентов со второй и третьей госпитализациями (F20.016) $41 \%(\mathrm{n}=55)$. Оставшиеся 18,7\% (n=25) представлены группой больных шизоаффективным расстройством (F25).

Основные методы нашего исследования представлены клинико-психопатологическим, психометрическим и статистическим. 
Для объективизации и количественной оценки психического состояния пациентов нами использована «Шкала позитивных и негативных синдромов» PANSS (Positive and Negative Syndrom Scale). Оценка социального функционирования проводилась с помощью «Шкалы личного и социального функционирования» PSP (Personal and Social Performance). Изучение и количественная оценка внутренней стигмы, а также трех ее конструктов (аутопсихическая, социореверсивная и компенсаторная формы) проводились в ПО «SS Measure» для ПК [13], основанном на «Опроснике по самостигматизации» [14]. Основным инструментом исследования явилась разработанная нами «Базисная карта пациента с первым психотическим эпизодом при шизофрении (изучение самостигматизации)».

В соответствии с научными взглядами Г.В. Логвинович и А.В. Семке [15] в собственном исследовании нами определены типы адаптации, а также компенсаторно-приспособительные реакции пациентов с первым психотическим эпизодом.

Статистическая обработка данных проводилась в пакете ПО SPSS Statistics 23. Анализ распределения частот категориальных переменных проводился с помощью критерия хи-квадрат и точного критерия Фишера. Распределение значений количественных переменных было изучено с помощью критериев Колмогорова-Смирнова и Шапиро-Уилка. Ни одна из рассматриваемых нами количественных переменных не соответствовала закону о нормальности распределения. Значимость различий в независимых выборках с распределением показателей, отличных от нормального, определялась с помощью непараметрического критерия Краскала-Уоллеса и вычислением медианы и квартилей (Me [Q1; Q3]).

\section{РЕЗУЛЬТАТЫ И ОБСУЖДЕНИЕ}

В ходе проведенного нами исследования было изучено взаимодействие и взаимовлияние социального функционирования, которое оценивалось согласно шкале PSP, а также клинических и социальных уровней адаптации [15] с использованием корреляционного анализа Кендалла. При этом была обнаружена сильная прямая положительная корреляция между показателями социального функционирования и клиническими уровнями адаптации (Tay=0,661; p<0,001). Кроме того, сильная положительная корреляционная связь обнаружена между социальными уровнями адаптации и количеством баллов по шкале PSP (Tay=0,653; p<0,001). Анализируя полученные результаты, можно сказать, что между выраженностью клинических проявлений заболевания и адаптационными возможностями пациента определена значимая взаимосвязь. Так, например, чем более выраженной была продуктивная и негативная симптоматика, тем менее социализирован пациент.

Вместе с тем нами проведено изучение распределения пациентов в выборке в зависимости от одного из четырех вариантов компенсаторноприспособительной защиты [15]: гуттаперчевая за- щитная капсула, укрытие под опекой, социальная оппозиция и экологическая ниша. На пациентов c «гуттаперчевой защитной капсулой», «экологической нишей» и «укрытием под опекой» приходился равный объем в выборке (по $30,6 \%, \mathrm{n}=41$ ). Для пациентов с типом компенсаторно-приспособительной защиты «социальная оппозиция» доля составила $8,2 \%(\mathrm{n}=11)$. Такое распределение, вероятно, связано с длительностью заболевания, выраженностью его клинических проявлений, наличием поддержки со стороны родных и близких.

Кроме того, в изучаемой выборке больных исследованы четыре типа адаптации: интегративный, деструктивный, интравертный и экстравертный. Первый тип, интегративный, занимал наибольший объем 83,6\% (n=112). На экстравертный и интравертный типы приходилось равное количество пациентов - по 4,5\% (n=6). Примечательно, что доля деструктивного типа адаптации оказалась незначительной $-7,5 \%(\mathrm{n}=10)$. Известно, что интегративный тип социально-трудовой адаптации характеризуется сочетанием компенсированных клинического и социального уровней, что в свою очередь связано с продолжительностью заболевания и степенью сохранности личности пациента. Этим можно объяснить выраженное преобладание среди пациентов с первым психотическим эпизодом данного типа адаптации.

При изучении самостигматизации и ее связи с вышеуказанными типами адаптации и вариантами компенсаторно-приспособительной реакции были получены следующие результаты. Обнаружена статистически значимая разница показателя самостигматизации в группах пациентов с различными типами адаптации $(\mathrm{p}=0,001)$. Однако сравнение той же переменной между когортами больных, сформированными по типу компенсаторно-приспособительной реакции, не обнаружило статистически значимых различий $(\mathrm{p}=0,294)$. Вместе с тем точный критерий Фишера показал наличие статистически значимых различий между типами адаптации в зависимости от типа компенсаторно-приспособительной реакции $(\mathrm{p}=0,012)$. Полученные результаты позволяют выдвинуть предположение о вероятной косвенной связи внутренней стигмы и компенсаторно-приспособительной реакции.

Примечательно, что самостигматизация оказалась менее выражена среди пациентов с интегративным и экстравертным типами адаптации (49 [26; 95] и $22[18,75 ; 48,5]$ балла соответственно). Наиболее «стигматизированными» оказались пациенты с интровертным (74 [55; 162] балла) и деструктивным $(116,5[102,75 ; 145]$ балла) типами адаптации. Таким образом, учитывая то, что интегративный и экстравертный типы адаптации характеризуются наличием адаптированных социальных уровней, можно предположить, что самостигматизация в большей степени зависит от уровня социализации пациента, его взаимодействия с микро- и макроокружением, чем от клинических проявлений заболевания. 
В дополнение к вышесказанному нами были изучены особенности показателей самостигматиза- ции в группах пациентов, разделенных в зависимости от полученного образования (рис. 1).

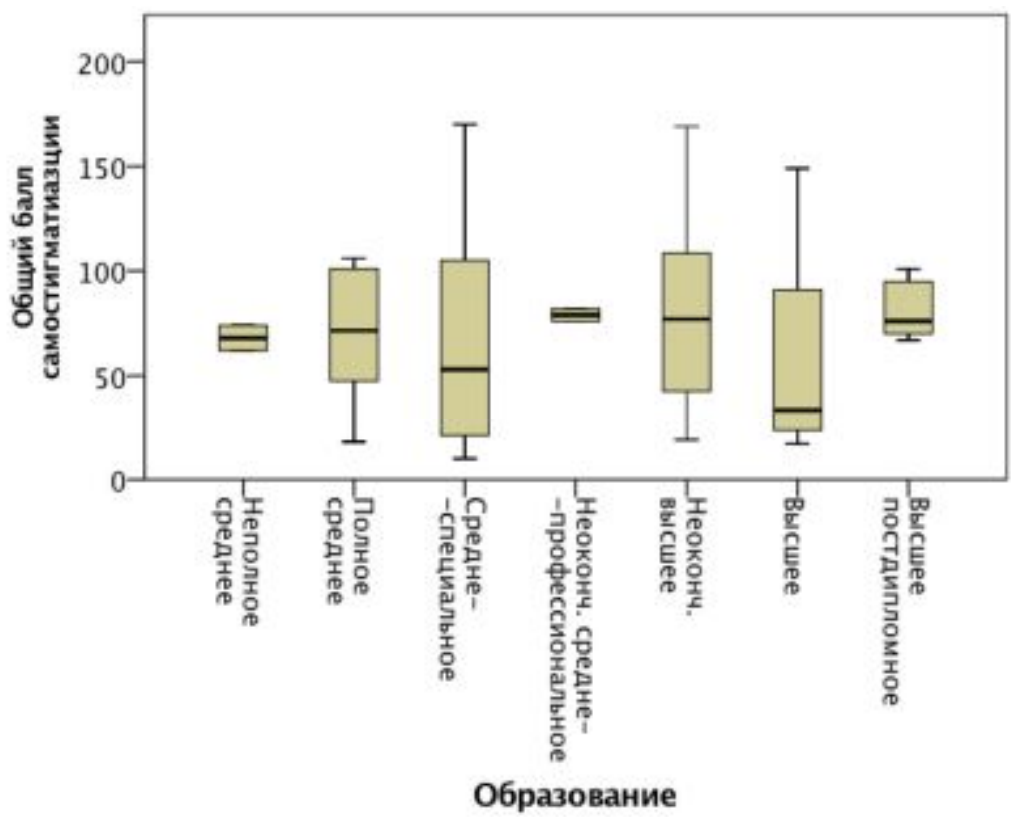

Р и с у н о к 1 . Общий балл самостигматизации в группах пациентов с разным уровнем образования

Так, в число наименее стигматизированных вошли пациенты с оконченным высшим образованием $(38,8 \%, n=52)$, медиана стигмы у которых составила 33,5 [23,25; 92] балла. Наибольшее значение общего балла самостигматизации представлено в группе лиц с неоконченным высшим образованием (10,4\%, $\mathrm{n}=14)$, что составило $80[43,75 ; 122,5]$ баллов, а также среди прошедших постдипломную подготовку в аспирантуре, магистратуре или в бакалавриате
$(4,5 \%, n=6)$. Значение внутренней стигмы в данной группе составило 76 [69,25; 96,5] баллов. При этом различия не обнаружили статистическую значимость, что установлено при сравнении показателей между группами с использованием критерия Краскала-Уоллиса $(\mathrm{p}=0,257)$. В данном случае роль уровня образования в формировании и поддержании переживаний пациентом внутренней стигмы представляется несколько сомнительной.

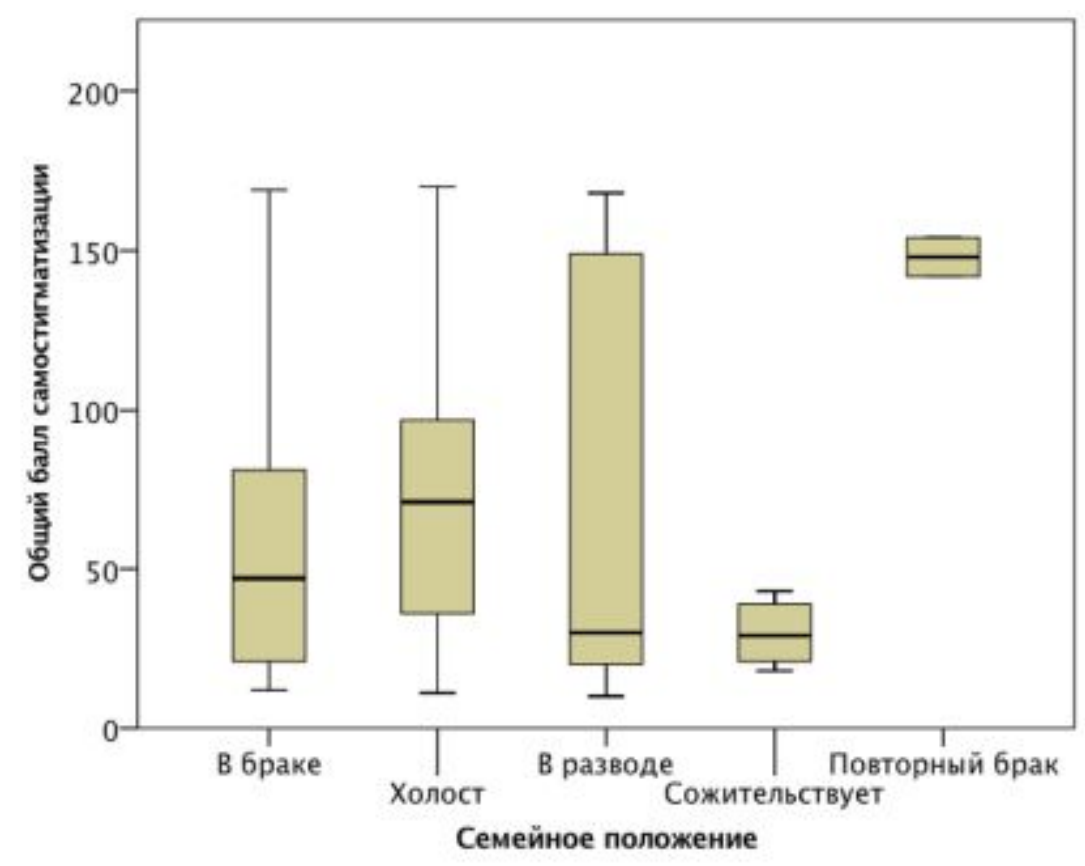

Р и с у н о к 2. Общий балл самостигматизации в группах пациентов с разным семейным положением 
Последующий анализ полученных данных показал отсутствие статистически значимых различий внутренней стигмы в группах пациентов с разным родом занятий: работник физического труда, умственного труда либо имеющий группу инвалидности. Однако при оценке стигмы в группах лиц с различным семейным положением были установлены статистически значимые различия (рис. 2).

Так, менее выраженная стигма $(29$ [20,5; 41] баллов) была выявлена среди тех, кто без заключения официального брака сожительствовал с партнером. Наибольшая выраженность самостигматизации (71 [36; 98] балл) была обнаружена среди пациентов, не состоящих в браке и не имеющих семейных отношений на момент обследования. В данном случае уместно предполагать, что определенную роль как в профилактике, так и формировании переживания внутренней стигмы играет факт наличия партнера или сожителя. Их роль, вероятно, значима для оказания поддержки пациенту.

Между группами больных, выросших либо с отцом, либо без него или с отчимом статистически значимые различия обнаружены не были. Выявлена значимая роль матери или мачехи в выраженности стигмы. Так, наибольшее значение самостигматизации $(59$ [31; 100,25] баллов) определено среди тех больных, кто воспитывался в полной семье, с матерью.

Особенности воспитания в семьях пациентов так же, вероятно, влияют на выраженность самостигматизации. Нами установлено различие значений общего балла стигмы в группах пациентов из семей с различными особенностями воспитания $(\mathrm{p}=0,042)$. В семьях, где имели место быть частые семейные скандалы родителей, алкоголизация, воспитание в условиях повышенной моральной ответственности, количественный показатель самостигматизации составил наибольшее значение $(82,5$ [38,25; 105] балла).

Психопатологически отягощенная наследственность, так же как и стиль воспитания, находила свое отражение в уровне самостигматизации. Установлено, что наибольшее значение стигмы имеет место среди пациентов, наследственный анамнез которых отягощен алкоголизмом со стороны отца (82,5 [71; 133] балла) и психопатоподобным поведением со стороны матери $(147,5$ [78,5; 157,75] балла). Полученные результаты могут быть объяснены ожиданием пациента негативного отношения и, соответственно, грубой реакции родителей на информацию о психическом заболевании их сына либо дочери, что, в свою очередь, продолжает оставаться распространённым явлением даже в современных семьях больных душевными расстройствами.

\section{ВЫВОДЫ}

Результаты нашего исследования подтверждают многофакторную природу самостигматизации. Установлена значимая роль социальнопсихологических факторов в проявлении внутренней стигмы. По всей вероятности, опосредованное влияние стигмы на вариант компенсаторноприспособительной защиты и социальное функционирование пациентов с первым психотическим эпизодом при шизофрении и шизоаффективным расстройством. Для уточнения результатов необходимо дальнейшее изучение внутренней стигмы, социального функционирования, адаптации и социальнопсихологических факторов. Полученные данные позволят разработать дифференцированные программы реабилитации для данной когорты больных.

\section{КОНФЛИКТ ИНТЕРЕСОВ}

Авторы заявляют об отсутствии конфликта интересов в связи с публикацией данной статьи.

\section{ИСТОЧНИК ФИНАНСИРОВАНИЯ}

Авторы заявляют об отсутствии финансирования при проведении исследования.

\section{СООТВЕТСТВИЕ ПРИНЦИПАМ ЭТИКИ}

Работа соответствует этическим стандартам Хельсинской декларации ВМА (протокол заседания этического комитета ФГБОУ ВО «Омский государственный медицинский университет» № 72 от 21 сентября 2015 г.).

\section{ЛИТЕРАТУРА}

1. Коцюбинский А.П., Еричев А.Н., Клайман В.О., Шмонина О.Д. Биопсихосоциальная модель шизофрении и ранние неадаптивные схемы. Часть 1. Уязвимость-диатез-стресс. Обозрение психиатрии и медицинской психологии имени В.М. Бехтерева. 2016; 2: 3-7.

2. Семке А.В., Федоренко О.Ю., Лобачева О.А., Рахмазова Л.Д., Корнетова Е.Г., Смирнова Л.П., Микилев Ф.Ф., Щигорева Ю.Г. Клинические, эпидемиологические и биологические предпосылки адаптации больных шизофренией как основа персонифицированного подхода к антипсихотической терапии. Сибирский вестник психиатрии и наркологии. 2015; 3 (88): 19-25.

3. Семке А.В., Микелев Ф.Ф. Клинико-социальные характеристики пациентов, страдающих расстройствами шизофренического спектра с ипохондрической симптоматикой. Сибирский вестник психиатрии и наркологии. 2013; 5 (80): 40-44.

4. Fujii T., Hanya M., Kishi M., Kondo Y., Cates M.E., Kamei H. An internet-based survey in Japan concerning social distance and stigmatization toward the mentally ill among doctors, nurses, pharmacists, and the general public. Asian J Psychiatr. 2018; 36: 1-7. doi: 10.1016/j.ajp.2018.05.017

5. Khoirunnisa M.L., Syuhaimie Hamid A.Y., Catharina Daulima N.H. Family experiences in communicating with family members experiencing social isolation after hospitalization. Enferm Clin. 2018 Feb; 28 Suppl 1: 116-121. doi: 10.1016/S11308621(18)30049-4

6. Zäske H., Linden M., Degner D., Jockers-Scherübl M., Klingberg S., Klosterkötter J., Maier W., Möller H.J., Sauer H., Schmitt A., Gaebel W. Stigma experiences and perceived stigma in patients with first-episode schizophrenia in the course of 1 year after their first in-patient treatment. Eur Arch Psychiatry Clin Neurosci. 2018; Apr 25. doi: 10.1007/s00406-018-0892-4

7. Ениколопов С.Н. Стигматизация и проблема психического здоровья. Медицинская (клиническая) психология: традиции и перспективы (К 85-летию Юрия Федоровича Полякова). М., 2013: 109-121.

8. Положий Б.С., Руженкова В.В. Стигматизация и самостигматизация больных шизофренией и шизоаффективным расстройством с суицидальным поведением. Научные ведомости БелГУ. Сер. Медицина. Фармаџия. 2015; 4 (201-29): 4956.

9. Link B.G., Struening E.L., Rahav M. On stigma and its consequences: evidence from a longitudinal study of men with dual diagnosis mental illness and substance abuse. Journal of Health and Social Behaviour. 1997; 38: 177-190. 
10. Крупченко Д.А., Крюк Н.В., Будник Т.А., Винклер П., Кравцова О.И., Мурин А.Я., Янковская А.Г. Семейная стигма при шизофрении в Республике Беларусь. Психиатрия, пси хотерапия и клиническая психология. 2015; 4 (22): 10-25.

11. Лутова Н.Б., Сорокин М.Ю., Вид В.Д. Психиатрическая стигма - ее проявления и последствия. Обозрение психиатрии и медицинской психологии имени В.М. Бехтерева. 2017; 2: 41-45.

12. Гурович И. Я., Шмуклер А. Б., Сторожакова Я. А. Психосоциальная терапия и психосоциальная реабилитация психически больных. Российский психиатрический журнал. 2006; 2: 61-64.

13. Дроздовский Ю.В., Васильченко К.Ф., Гавричкин А.В. ФГБОУ ВО ОмГМУ Минздрава России. SS Measure. Свиде- тельство о государственной регистрации программы для ЭВМ № 2018614169; Заявл. № 2017663150 18.12.2017; Регистр. 2.04.2018.

14. Ястребов В.С., Ениколопов С.Н., Михайлова И.И. Самостигматизация больных при основных психических заболеваниях. Журнал невропатологии и психиатрии им. С.С. Корсакова. $2005 ; 105$ (11): 50-54

15. Логвинович Г.В., Семке А.В. Первичные и вторичные нарушения адаптации при шизофрении. Томск, 1995: 216.

Поступила в редакцию 7.05.2018 Утверждена к печати 25.06.2018

Васильченко Кирилл Федорович, аспирант кафедры психиатрии, медицинской психологии.

Дроздовский Юрий Викентьевич, д.м.н., профессор, заведующий кафедрой психиатрии, медицинской психологии.

Васильченко Кирилл Федорович, kirill.f.vasilchenko@gmail.com

For citation: Vasilchenko K.F., Drozdovsky Yu.V. Social functioning and adaptation of patients with the first psychotic episode: internalized stigma, social and psychological factors. Siberian Herald of Psychiatry and Addiction Psychiatry. $2018 ; 3$ (100): 1015. https://doi.org/10.26617/1810-3111-2018-3(100)-10-15

\section{Social functioning and adaptation of patients with the first psychotic episode: internalized stigma, social and psychological factors Vasilchenko K.F., Drozdovsky Yu.V.}

Omsk State Medical University

Lenin Avenue 12, 644043, Omsk, Russian Federation

\section{ABSTRACT}

In the article results of the investigation of the internalized stigma and social functioning among patients with schizophrenia and schizoaffective disorder are shown. Objective of the study is the development of rehabilitation for early episode patients with schizophrenia and schizoaffective disorder, based on the evaluation of their social functioning, adaptation, internalized stigma, social and psychologic factors. Methods. Sample - 134 patients with early episode of schizophrenia or schizoaffective disorder. Clinical and psychopathological, psychometric (PANSS, PSP, "SS Measure»") and statistical methods are used. The significant differences of the internalized stigma respective from the upbringing type, family history, marital status, education and compensatory-coping defenses are found.

\section{Keywords: schizophrenia, internalized stigma, early episode, social functioning, adaptation.}

\section{REFERENCES}

1. Kotsyubinsky A.P., Erichev A.N., Klaiman V.O., Shmonina O.D. Biopsihosocial'naja model' shizofrenii i rannie neadaptivnye shemy. Chast' 1 . Ujazvimost'-diatez-stress [Biopsychosocial model of schizophrenia and early maladaptive schemas. Part 1. Vulnerability-diathesis-stress]. Obozrenie psihiatrii i medicinskoj psihologii imeni V.M. Behtereva - V.M. Bekhterev Review of Psychiatry and Medical Psychology. 2016; 2: 3-7 (in Russian).

2. Semke A.V., Fedorenko O.Yu., Lobacheva O.A., Rakhmazova L.D., Kornetova E.G., Smirnova L.P., Mikilev F.F., Shchigoreva Yu.G. Klinicheskie, jepidemiologicheskie i biologicheskie predposylki adaptacii bol'nyh shizofreniej kak osnova personificirovannogo podhoda $\mathrm{k}$ antipsihoticheskoj terapii [Clinical, epidemiological and biological preconditions of adaptation of patients with schizophrenia as a basis for personified approach to antipsychotic therapy]. Sibirskij vestnik psihiatrii i narkologii Siberian Herald of Psychiatry and Addiction Psychiatry. 2015; 3 (88): 19-25 (in Russian).

3. Semke A.V., Mikelev F.F. Klinikosocial'nye harakteristiki pacientov, stradajushhih rasstrojstvami shizofrenicheskogo spektra s ipohondricheskoj simptomatikoj [Clinical and social characteristics of patients with schizophrenia spectrum disorders with severe hypochondriac symptoms]. Sibirskij vestnik psihiatrii $i$ narkologii - Siberian Herald of Psychiatry and Addiction Psychiatry. 2013; 5 (80): 40-44 (in Russian).
4. Fujii T., Hanya M., Kishi M., Kondo Y., Cates M.E., Kamei H. An internet-based survey in Japan concerning social distance and stigmatization toward the mentally ill among doctors, nurses, pharmacists, and the general public. Asian J Psychiatr. 2018; 36: 1-7. doi: 10.1016/j.ajp.2018.05.017.

5. Khoirunnisa M.L., Syuhaimie Hamid A.Y., Catharina Daulima N.H. Family experiences in communicating with family members experiencing social isolation after hospitalization. Enferm Clin. 2018 Feb; 28 Suppl 1: 116-121. doi: 10.1016/S11308621(18)30049-4

6. Zäske H., Linden M., Degner D., Jockers-Scherübl M., Klingberg S., Klosterkötter J., Maier W., Möller H.J., Sauer H., Schmitt A., Gaebel W. Stigma experiences and perceived stigma in patients with first-episode schizophrenia in the course of 1 year after their first in-patient treatment. Eur Arch Psychiatry Clin Neurosci. 2018; Apr 25. doi: 10.1007/s00406-018-0892-4

7. Enikolopov S.N. Stigmatizacija i problema psihicheskogo zdorov'ja [Stigma and mental health problem]. Medicinskaja (klinicheskaja) psihologija: tradicii i perspektivy (K 85-letiju Jurija Fedorovicha Poljakova). Moskow, 2013: 109-121 (in Russian).

8. Polozhij B.S., Ruzhenkova V.V. Stigmatizacija i samostigmatizacija bol'nyh shizofreniej i shizoaffektivnym rasstrojstvom $s$ suicidal'nym povedeniem [Stigma and self-stigma of schizophrenia and schizoaffective disorder patients with suicidal behaviour]. Nauchnye vedomosti BelGU. Ser. Medicina. Farmacija 
- Scientific News of BelSU Ser. Medicine. Farmacy. 2015; 4 (201-29): 49-56 (in Russian).

9. Link B.G., Struening E.L., Rahav M. On stigma and its consequences: evidence from a longitudinal study of men with dual diagnosis mental illness and substance abuse. Journal of Health and Social Behaviour. 1997; 38: 177-190.

10. Krupchenko D.A., Kryuk N.V., Budnik T.A., Vinkler P., Kravtsova O.I., Murin A.Ya., Yankovskaya A.G. Semejnaja stigma pri shizofrenii v Respublike Belarus' [Family stigma in schizophrenia in The Republic of Belarus]. Psihiatrija, psihoterapija $i$ klinicheskaja psihologija - Psychiatry, Psychotherapy and Clinical Psychology. 2015; 4 (22): 10-25 (in Russian).

11. Lutova N.B., Sorokin M.Yu., Vid V.D. Psihiatricheskaja stigma - ee projavlenija i posledstvija [Stigma in patients with mental disorders - its manifestations and consequences]. Obozrenie psihiatrii i medicinskoj psihologii imeni V.M. Behtereva - V.M. Bekhterev Review of Psychiatry and Medical Psychology. 2017; 2: 41-45 (in Russian).

12. Gurovich I.Ya., Shmukler A.B., Storozhakova Ya.A. Psihosocial'naja terapija i psihosocial'naja reabilitacija psihicheski bol'n- yh [Psychosocial treatment and psychosocial rehabilitation of mental health patients]. Rossiyskiy psihiatriceskiy zhurnal - Russian Journal of Psychiatry. 2006; 2: 61-64 (in Russian).

13. Drozdovsky Yu.V, Vasilchenko K.F., Gavrichkin A.V. SS Measure. Russian Federation certificate of application for PC RU 2018614169. 2018 Apr 2. Russian.

14. Yastrebov V.S., Enikolopov S.N., Mikhailova I.I. Samostigmatizacija bol'nyh pri osnovnyh psihicheskih zabolevanijah [Self stigma of main mental disorders patients]. Zhurnal nevropatologii i psihiatrii imeni S.S. Korsakova - S.S. Korsakov Journal of Neuropathology and Psychiatry. 2005; 105 (11): 5054 (in Russian).

15. Logvinovich G.V., Semke A.V. Pervichnye i vtorichnye narushenija adaptacii pri shizofrenii [Primary and secondary adaptation disorders in schizophrenia]. Tomsk, 1995: 216 (in Russian).

Received May 7.2018 Accepted June 25.2018

Vasilchenko Kirill F., post-graduate student of the Department of Psychiatry and Medical Psychology, Omsk State Medical University, Omsk, Russian Federation

Drozdovsky Yury V., M.D., Professor, Head of Department of Psychiatry and Medical Psychology, Omsk State Medical University, Omsk, Russian Federation.

Vasilchenko Kirill F., kirill.f.vasilchenko@gmail.com 